\title{
CONSIDERAÇÕES SOBREE A SONDAGEM GÁSTRICA NO RECÉM-NASCIDO
}

\author{
Miriam Aparecida Barbosa Merighi* \\ Zaida Aurora Sperli Gerades Soler**
}

\begin{abstract}
MERIGHI, M.A.B. \& SOLER, Z.A.S.G. Consideraçð̌es atuais sobre a sondagem gástrica no recém-nascido. Rev. Esc. Enf. USP, São Paulo, 22(3): 289-297, dez. 1988.

Neste trabalho destaca-se a importância da assistência criteriosa ao recém-nascido submetido a sondagem gástrica. Para isso, com base na experiência das autoras e nas recomendaçóes de diversos pesquisadores, descrevem-se os procedimentos necessários para a realizaçâo dessa conduta terapêutica.
\end{abstract}

UNITERMOS: Intubação gastro-intestinal. Recém-nascido.

\section{INTRODUUÇÃO}

A utilização da sondagem gástrica, contínua ou.intermitente, é conduta comum nas unidades de neonatologia de alto risco. Este procedimento consiste na introdução de um cateter através das fossas nasais ou da boca, passando pela faringe e pelo esôfago até o estômago, alguns centímetros além do esfíncter do cárdia.

A finalidade da sondagem gástrica é proporcionar um método de alimentação ou de administração de medicamentos que exija um mínimo de esforço do neonato (quando existe incoordenação da sucção-deglutição, imaturidade, desconforto respiratório leve e nas malformaçôes congênitas que dificultam a sucção e/ou a deglutição).

Dada a importância e a responsabilidade da execução desta técnica, a sondagem deve ser realizada pelo médico ou pela enfermeira, já que a não observação correta da mesma pode trazer problemas sérios ao neonato, como, por exemplo, aspiração do alimento. Não se pode admitir que pessoas não qualificadas executem este cuidado e, no entanto, muitas vezes, é ela delegada ao pessoal auxiliar de enfermagem, inclusive às atendentes, como constatou MERIGHI'0.

Parece que nos berçários existe muita dificuldade quanto a pessoal, tanto em quantidade como em qualidade. Sabe-se que o ideal seria manter no cuidado ao recém-nascido apenas enfermeiros, técnicos e auxiliares de enfermagem. Contudo, isso é difícil em nosso meio, por haver escassez desses profissionais e por serem estes considerados muito onerosos pelas instituiçðes hospitalares.

Tal dificuldade obriga, geralmente, à utilização de pessoas que não possuem co-

* Enfermeira. Professor Assistente do Departamento de Enfermagen Materno-Infantil e Psiquiátrica da EEUSP, disciplina Enfermagem Ginecológica, Obstétrica e Neonatal.

** Enfermeira. Aluna do Curso de Pós-Graduação da EEUSP.

Rev. Esc. Enf. USP, São Paulo, 22(3):28j-288, dez. 1988 
nhecimentos cientificos básicos para essa assisıência e para a conıpreensão de determinadas situaçòes que requerem atendinento imediato.

Convém ressaltar que, apesar da evolução dos conhecimentos enı neonatologia e do progresso com a utilização de equipamentos eletrônicos, foram pequenas as mudanças nos procedinıentos técnicos de atendimento ao recém-nascido.

No presente trabalho consideramos somente a técnica da sondagem gástrica. Pelo que observamos, geralmente este procedimento é aprendido no dia-a-dia do trabalho, con orientação recebida, ano após ano, baseada nas normas e rotinas da unidade de berçário. Poucas são as ocasiōes em que é realizada pesquisa ou são levados em consideração estudos atuais, quando da elaboração para o serviço, normas mais aprimoradas de execução desse procedimento.

Acresce que, na revisão da literatura sobre os procedimentos para intubação gástrica, constatamos que os autores divergem quanto ao que é preconizado sobre tal técnica, principalmente no que se refere à medida da sonda e ao uso de lubrificante.

No tocante ao tamanho da sonda, os autores DISON ${ }^{4}, \mathrm{HOWARD}^{7}$, ORLANDI ${ }^{\prime \prime}$, WATANABE et alii $^{1+}$ e ZIEGEL \& CRANLEY ${ }^{16}$, entre outros, recomendam, como medida, a distância da glabela ao apêndice xifóide; BATES ${ }^{2}$ mede do apêndice xifóide à glabela e acrescenta 6 centímetros; HUGHES \& BUESCHER ${ }^{4}$ tomam como referência a extremidade distal da sonda 5 a 8 centímetros abaixo do apêndice xifóide, medindo até as narinas do recém-nascido; WAECHTER \& BALLARD ${ }^{13}$ acham que a extensão necessária da sonda para atingir o estômago deve ser a medida da ponta do nariz ao lóbulo da orelha e daí à extremidade do esterno; COX \& FANAROFF ${ }^{n}$ e KLAUSS \& THRIFT $^{3}$ usam como medida a distância entre o apêndice xifóde e o lóbulo da orelha e acrescentam a distância da orelha até o nariz; WILLET et alii's, ZIEMER \& CARROL ${ }^{17}$ acham que as medidas convencionais são curtas e recomendam a medida determinada pela distância da ponta do nariz ao lóbulo da orelha e, deste local até o ponto médio entre o apêndice xifóide e a cicatriz umbilical; para DUGAS ${ }^{5}$, a sonda deve ser medida do nariz ao lóbulo da orelha e desta à cicatriz umbilical.

Quanto ao uso de lubrificantes AVERY', BATES ${ }^{2}$, DISON $^{4}$, DUGAS $^{5}$, HUGHES \& BUESCHER ${ }^{9}$, PHILIP ${ }^{12}$, WAECHTER \& BALLARD ${ }^{13}$, ZIEGEL \& CRANLEY ${ }^{16}$ esclarecem que não se pode usar material oleoso por causa do risco da pneumonia lipídica se o tubo lubrificado penetra inadvertidamente na traquéia; acrescentam que, no entanto, muitas vezes, a lubrificação da sonda é necessária para diminuir o atrito entre a mucosa nasal e o cateter e, que, nestes casos, a lubrificação deve ser feita com água, soro fisiológico ou substância hidrossolúvel; GOULART ${ }^{7}$ indica como lubrificantes da sonda gástrica, o soro fisiológico, a vaselina ou a glicerina. Já ZIEMER \& CARROL ${ }^{17}$ acham desnecessário o uso de lubrificantes para a sonda, pois a mucosa gastrointestinal possui lubrificação adequada.

$\mathrm{Na}$ nossa atividade diária, o que temos observado sobre a assistência prestada ao recém-nascido com gavagem nos preocupa. Portanto, nossos objetivos neste trabalho são:

1. alertar a enfermeira responsável pela unidade de neonatologia para:

- orientar, treinar e supervisionar os técnicos e auxiliares de enfermagem que executam essa atividade;

- rever se essa técnica pode continuar como atribuição das pessoas que a desempenham, no seu local de trabalho; 
2. descrever os procedimentos necessários à assistência criteriosa do recémnascido submetido à sondagem gástrica, baseando-se em estudos recentes.

De acordo com nossa experiência e com base no estudo da literatura sobre o assunto, a assistência de enfermagem que recomendamos para os recém-nascidos com prescrição de gavagem pode ser descrita como segue:

1. Verificar, na prescrição médica, o tipo de intubação gástrica (oral ou nasal) e a fórmula láctea a ser administrada.

2. Preparar o material a ser usado:

- seringa esterilizada de 10 ou $20 \mathrm{ml}$;

- sondas gástricas infantis de polietileno, de número 4,5 e 6 , de ponta arredondada e furos na ponta terminal. Escolher a sonda de diâmetro adequado para o neonato, a fim de evitar dificuldades tanto na sua colocação como no seu funcionamento; para a sondagem orogástrica pode-se utilizar um cateter de maior calibre (número 8); a passagem de sonda nasogástrica implica em escolher um cateter de calibre bem fino, lembrando que, se o tubo passar sem dificuldades pela narina, chegará facilmente ao estômago, já que o orifício nasal é o menor canal para se inserir um tubo.

A permeabilidade da sonda deve ser previamente testada com soro fisiológico ou água destilada; por diversas vezes encontramos sondas com uma película nos locais dos orifícios, sinal de que estavam obstruidas.

- esparadrapo ou, se possível, adesivo não alérgico para fixação da sonda;

- fórmula láctea ou medicamento prescrito;

- cuba com água, se necessário, para testar a localização da sonda.

3. Lavar as mãos, antes de manipular o recém-nascido;

4. Com todo o material previamente colocado junto ao neonato, examinar o local de inserção da sonda; se for a boca, limpá-la e, se necessário aspirar as secreções da orofaringe; se for realizada intubação nasogástrica, examinar as narinas, escolhendo a mais larga; se estiverem muito ressecadas, lubrificá-las com soro fisiológico.

5. Medir o cateter, determinando a distância necessária para a introdução até o terço médio do estômago. Como já foi visto, os autores recomendam medidas diferentes tanto para a sondagem oral como para a sondagem gástrica, a distância deve ser previamente marcada com esparadrapo, para se saber até onde introduzir a sonda, evitando-se colocar sua extremidade antes do estômago (risco de aspiraçăo) ou na parte gástrica final (diminuição ou falta de absorção do alimento no estômago). A medida que adotamos para sondagem gástrica, por via oral ou nasal, é a preconizada por ZIEMER \& CARROL ${ }^{17}$, que basearam seus estudos na verificação da localização da sonda no estômago de neomortos, durante o processo de necrópsia. As autoras constataram que, usando medidas convencionais como aquela da distância da ponta do nariz ao lóbulo da orelha e daí ao apêndice xifóide ou, da raiz do nariz à extremidade inferior do apêndice xifóide, o cateter ficava quase junto ao esfíncter do cárdia, ou pouco além, sendo, portanto, medidas curtas. Utilizando a medida da ponta do nariz ao lóbulo da orelha e daí até.o ponto médio entre o apêndice xifóide e a cicatriz umbilical (sondagem nasogástrica), ZIEMER \& CARROL ${ }^{17}$ verificaram 
que a sonda ficava localizada no terço médio do estômago, o que possibilita melhores condiçōes para avaliação do conteúdo gástrico, assim como para a administração de líquidos. Para a intubação oro-gástrica, essas autoras recomendam medir da ponta do nariz ao lóbulo da orelha e daí até a parte inferior do apêndice xifóide.

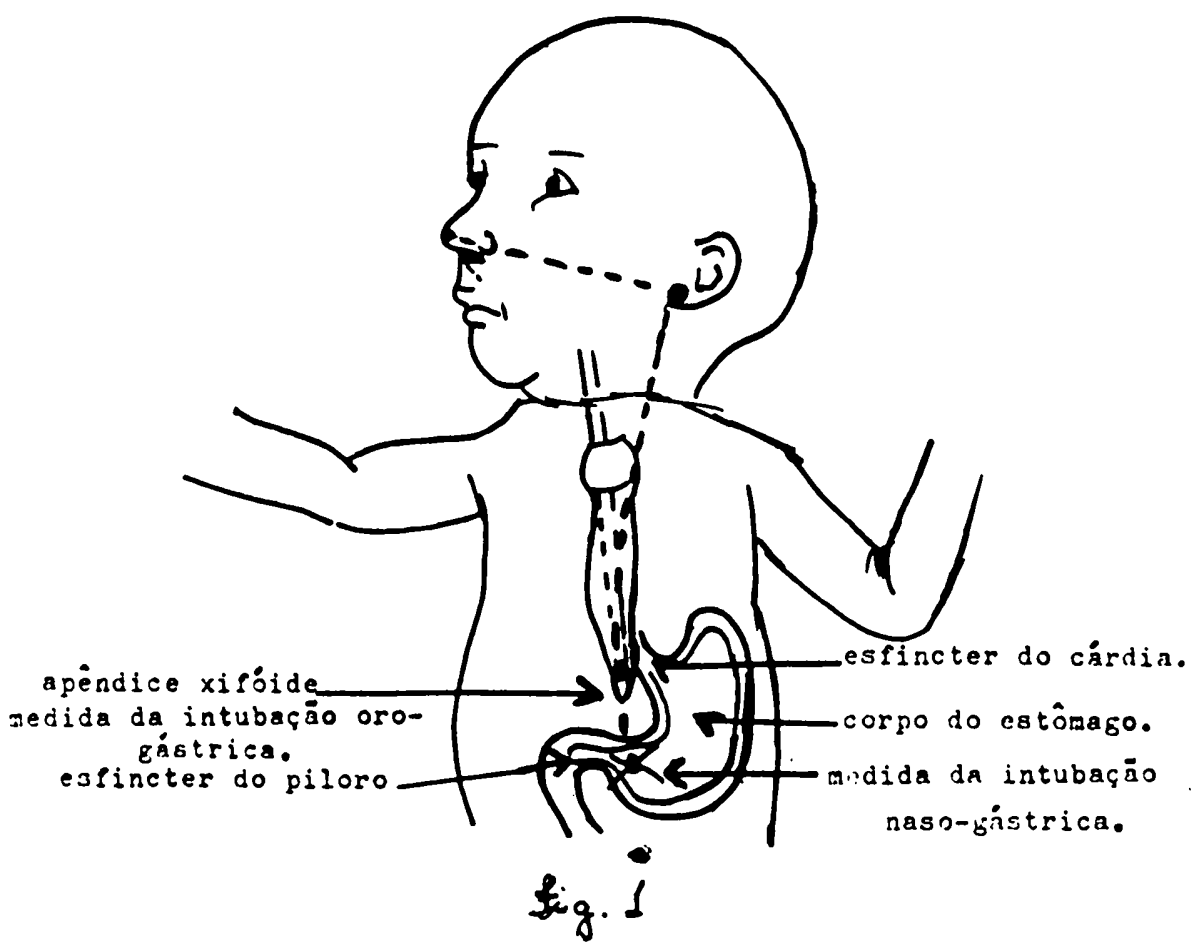

6. Verificar se há necessidade de lubrificar a sonda, para permitir a sua passagem mais suavemente, e diminuir o atrito entre o cateter e a mucosa nasal; se preciso, umedecer a extremidade distal da sonda com água, soro fisiológico ou substância hidrossolúvel; não usar lubrificante de base oleosa, pelo perigo de provocar um foco de irritação e pneumonia lipídica, se a sonda for inserida inadvertidamente na traquéia, conforme advertem BATES ${ }^{2}$, DISON ${ }^{4}$, DUGAS ${ }^{5}$, HUGHES \& BUESCHER $^{9}$, WAECHTER \& BALLARD ${ }^{13}$, e ZIEGEL \& CRANLEY ${ }^{16}$.

7. Colocar o recém-nascido em decúbito lateral (de preferência), ou dorsal, com a cabeça elevada e o corpo levemente inclinado para a direita.

8. Iniciar a introdução da sonda nasogástrica segurando com a mão a cabeça do neonato mantendo-a firme, e deixando o polegar livre para elevar a ponta do nariz, com o intuito de aumentar o orifício nasal externo.

Se for realizada sondagem oro-gástrica, inserir a sonda sobre a língua do neonato curvando-a no fundo da garganta.

Deslizar o cateter firme e cuidadosamente no interior da narina ao longo do assoalho do nariz, direcionando-o para o occipital. Nunca forçar a sonda ao encontrar 


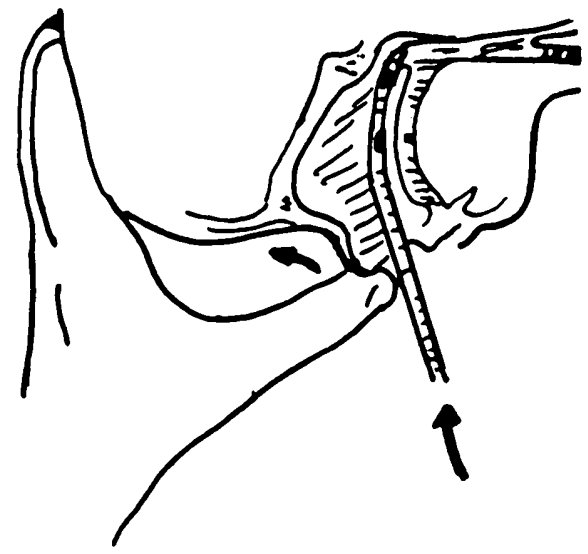

Fig. 2

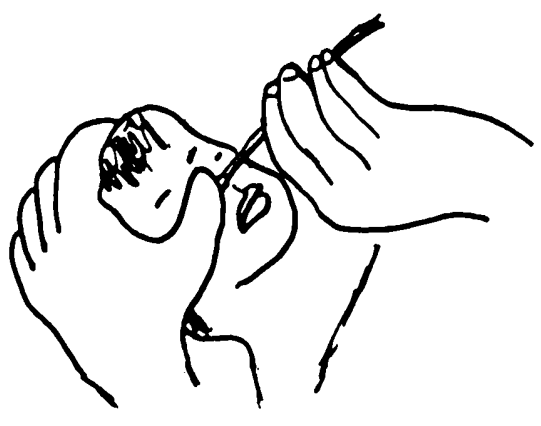

Fig. 3

resistência, pois isto pode provocar lesðes na mucosa nasal e, possivelmente, infecções. A flexão da cabeça durante a inserção da sonda ajudará a guiá-la através do esôfago. Caso o tubo se enrole na boca ou o recém-nascido engasgue ou comece a tossir, retire-o da nasofaringe, espere alguns segundos e recoloque-o. É prudente, ultrapassada a faringe, esperar cerca de 1 minuto antes de continuar a introduzir a sonda, observando sinais de tosse ou cianose, para certificar-se de que a sonda está realmente no estômago.

Enquanto se introduz a sonda deve-se observar qualquer sinal de estimulação vagal (bradicardia e apnéia). O trajeto do vago atravessa o pescoço, o tórax e o abdome. Acima do estômago, as ramificações da esquerda e da direita unem-se para formar o plexo esofágico. A estimulação dessas ramificaçðes nervosas com o cateter afetará diretamente o plexo cardíaco e pulmonar. Se acontecer o estímulo vagal deve-se fazer uma pausa de alguns minutos, enquanto se manipula o neonato para reanimá-lo.

9. Fixar a sonda com adesivo na face do recém-nascido, após a introdução do cateter até a medida pré-determinada; (Fig.4) isso evita que o cateter saia da medida previamente especificada. Ao fixar a sonda na regiăo nasogeniana, deve-se evitar que ela faça pressão sobre a asa do nariz, o que pode resultar em necrose deste local. Também, deve-se ter o cuidado de não ocluir a narina oposta ao se fixar a sonda, pois no recém-nascido a respiração é essencialmente nasal; aliás, esse é o principal motivo de se eleger a intubação gástrica por via oral no recém-nascido muito pequeno.

10. Verificar se o cateter está no estômago. O estômago nunca está completamente vazio, ele sempre contém pelo menos um pouco de suco gástrico. A obtenção de elementos do conteúdo gástrico, por aspiração comprova que a sonda está no estômago. Segundo DISON 4 , o método mais acurado para se determinar a exata localização do cateter é usar tubo radiopaco e procurar vê-lo com fluoroscópio.

A não obtenção do conteúdo estomacal pela aspiração não indíca, conclusivamente, que a sonda não esteja no estômago; mudando-se a posição do recém- 
nascido ou avançando-se a sonda, pode-se colocar o cateter em contato com o conteúdo estomacal.

Podem ser realizados os seguintes testes se, ao aspirar a sonda não se puder conseguir suco gástrico ou resíduo de formula láctea:

a) colocar a parte terminal da sonda, aberta, em um recipiente com água. $\mathrm{A}$ ausência de bolhas indica que a sonda tem localização gástrica, bolhas rítmicas indicam que a sonda está na traquéia - neste caso, retira-se a sonda rapidamente.

b) injetar 1 a 2 mililitros de ar no estômago. Simultaneamente, colocar o estetoscópio na região epigástrica para escutar o ruído do ar no estômago (escuta-se som de "estouro" quando o ar penetra no estômago). Depois, aspirar o ar injetado, para evitar a distensão abdominal.

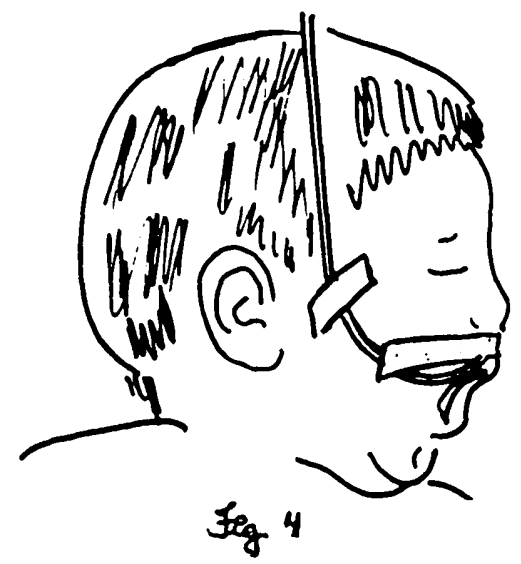

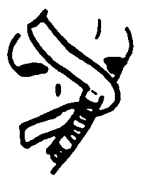

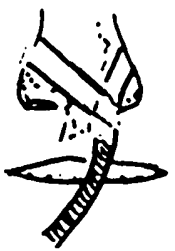

Iig. 5

11. Realizar a aspiração do conteúdo gástrico ou a introdução de líquidos. Se a sondagem gástrica for feita para a administração de líquidos, deve-se proceder, inicialmente, a retirada do resíduo gástrico; os residuos de fórmula láctea obtidos devem ser reintroduzidos e subtraido o volume coletado do total que foi prescrito para ser administrado.

Os autores recomendam que os líquidos sejam administrados por gravidade. Nesse caso, retira-se o êmbolo da seringa, adaptando-se o corpo da mesma à sonda; levando-se o cateter 10 a 15 centímetros acima da cabeça do recém-nascido, despejase o líquido na seringa, retira-se o "clampeamento" da sonda, feito inicialmente para evitar a entrada de ar no estômago, e deixa-se o líquido escoar lentamente até que seja administrado todo o volume prescrito. Deve-se lembrar que o calibre do cateter controla a velocidade do fluxo (quanto menor o calibre mais lento será o fluxo); também a altura do reservatório do líquido pode determinar alterações na velocidade da infusão, já que, se ficar muito alto, a pressão do líquido, por si só, aumenta a velocidade do fluxo.

Não se recomenda a administração de líquidos por intermédio de seringa com êmbolo pelo perigo de injetar a solução por pressão positiva e com maior velocidade. No entanto, na prática utiliza-se mais esse método, desde que o líquido seja administrado lentamente, com pausas, para que sejam avaliadas as condiçōes do neonato, determinando uma infusão mais lenta que a verificada por ação da gravidade.

Pudemos, muitas vezes, observar que os recipientes são ajustados acima do neonato, e o liquido é introduzido por pressão negativa, sem estar o funcionário observando o recém-nascido durante todo o procedimento. 
12. Injetar de 0,5 a 1 mililitro de água ou soro glicosado a $5 \%$ na sonda, para lavá-la e evitar que obstrua, após administração da fórmula láctea prescrita. Fechar a sonda rapidamente, para que não penetre ar no estômago, que cause distensão abdominal. Se a sonda for retirada na alimentação intermitente por gavagem, deve-se pinçá-la e retirá-la rapidamente, antes que o líquido pinge na faringe, e que o neonato $o$ aspire.

13. Fazer o neonato eructar, se possível; para isso, sua cabeça e seu tronco devem ser levantados, sustentados pela mão do funcionário. A expulsão adequada de ar engolido durante a sondagem gástrica reduzirá a distensão gástrica e possibilitará melhor tolerância à alimentação por gavagem.

14. Colocar o recém-nascido em decúbido ventral ou lateral direito, por 45 a 60 minutos, para reduzir a regurgitação e evitar a aspiração do líquido regurgitado.

15. Observar, com frequeência, o estado do neonato, pois ainda podem ocorrer bradicardia e apnéia, devido à estimulação vagal. Verifica-se, também, se há sinais de vômito, regurgitação, distensão abdominal, episódios frequentemente causados pela alimentação muito rápida ou em quantidade excessiva.

16. Anotar o processo no relatório de enfermagem, registrando com exatidão: via de sondagem; duração da administração; tipo e volume de líquido administrado; quantidade retida e expelida; resíduo gástrico; como o recém-nascido tolerou o procedimento; atividade do neonato posterior ao processo e intercorrências (regurgitação, vômitos, distensão abdominal, desconforto respiratório, bradicardia, cianose, etc.).

\section{OBSERVAÇÕES COMPLEMENTARES}

Se a sonda for mantida no estômago do neonato, deve-se aspirá-la sempre, antes de se iniciar a alimentação nos horários subseqüentes. Isto visa controlar a ingestão adequada de líquidos, o tempo da digestão e a superalimentação que possa causar distensão, além de evitar a infusão do líquido fora do estômago.

Quando se obtém resíduo da fórmula láctea, devolve-se o líquido ao estômago e subtrai-se essa quantidade do total a ser administrado. Se for obtido resíduo em volume igual ou superior à metade do líquido prescrito e administrado no horário anterior, solicita-se avaliação médica antes de se injetar o leite. Geralmente, quando o resíduo gástrico é de volume grande, suspende-se a alimentação daquele horário e suspeita-se da possibilidade da superalimentação.

A administração muito rápida do líquido, por gavagem, interferirá na peristalse, causando distensão abdominal e regurgitação ou vômitos. O período da infusão deve corresponder ao da duração da alimentação por mamadeira, considerando-se as peculiaridades do recém-nascido pré-termo ou débil.

A alimentação intermitente por gavagem deveria ser mais usada que a gavagem de demora. O cateter de demora, principalmente quando o uso é prolongado, pode enrolar, obstruir a via aérea nasal onde está inserido, causar incompetência do esfíncter cárdio-esofágico, epistaxe e inclusive perfurar o estômago. Se for preciso co- 
locar sonda gástrica de demora, deve-se trocar o cateter a cada 48 a 72 horas, alternando as narinas, assim como usando a via oral, nas substituiçðes.

Ao retirar a sonda, lembrar sempre de fechá-la, mediante pinçamento, para que não goteje na faringe o líquido retiradó na sonda, o que poderia causar a sua aspiração.

Aventar as complicaçðes que podem ocorrer no processo de sondagem gástrica: traumatismo do septo nasal; das coanas e adenóides; enrolamento do cateter na cavidade bucal; penetração da sonda na traquéia (causando tosse e dispnéia); retorno da sonda ao nivel do cárdia; incompetência cárdio-esofágica; lesão de asa do nariz por compressão, pela fixação inadequada da sonda.

Sonda com orifício de número e tamanho insuficientes não permitem drenagem adequada; orifícios grandes levam ao "acotovelamento" da sonda; a sonda pouco introduzida deixa os furos acima do esfíncter do cárdia levando o conteúdo gástrico ao esôfago e diminuindo a drenagem (esse erro é indicado pela oscilação de líquido na sonda, durante a respiração); sondas introduzidas além do ponto ideal podem penetrar no duodeno e enovelar-se no estômago.

\section{CONSIDERAÇÕES FINAIS}

Pelo exposto, percebe-se que a realização da sondagem gástrica requer a utilização de procedimentos específicos para que essa conduta terapêutica seja feita com precisão e não acarrete complicações graves para o neonato.

Acreditamos que este atendimento deveria ser prestado pela enfermeira ou pelo médico, ou senão, pelo técnico ou auxiliar de enfermagem adequadamente orientados, treinados e supervisionadas por enfermeiras, ao realizarem este procedimento.

Voltamos a alertar as enfermeiras responsáveis por unidade de neonatologia para que se atualizem permanentemente, estudando a literatura referente à sondagem gástrica e que reflitam sobre o fato de delegar essa atividade ao pessoal auxiliar, que pode não estar capacitado para tal.

MERIGHI, M.A.B. \& SOLER, A.A.S.G. Recent considerations on gastric gauvage in the newborn. Rev. Esc. Enf. USP, São Paulo, 22(3): 289-297, Dec. 1988.

This paper shows the importance of a criterious management of the newborn when rendering gastric gauvage. The description of this therapeutic procedure is based on the experience of the authors and on the recommendations of several researches.

UNITERMS: Intubation gastrointestinal. Newborn infant.

\section{REFERÊNCIAS BIBLIOGRÁFICAS}

1. AVERY, G.B. \& FLETCHER, A.B. Nutrição. In: AVERY, G.B. Neonatologia, fisiologia e cuidado do recém-nascido. São Paulo, Artes médicas, 1978. p.816-18.

2. BATES, S.M. Basic nursing care. In: well Scientific Publication, 1979. cap. 7, p.114-19.

3. COX, M.A. \& THRIFT, M.C. Alimentação. In: COX, J.P. \& STARK, A. R. Manual de assistencia ao rectm-nascido. Săo Paulo, Monole, 1982. cap. 27, p. 340-43. 
4. DISON, N. Gastric intubation and formula feedings. In: Clinical nursing techiniques.

3. ed. Saint Louis, Mosby, 1975. cap. 6, p.185-96.

5. DUGAS, B.W. Necessidades nutricionais. In: neiro, Interamericana, 1984. cap.11, p.203-206.

Enfermagem prática. 4. ed. Rio de Ja-

6. FANAROFF, A. \& KLAUS, M. O trato gastrintestinal - nutriçăo e distúrbios especiais. In: KLAUS, M. \& FANAROFF, A. Alto risco em neonatologia. 2. ed. Rio de Janeiro, Interamericana, 1982. cap.6, p.119-20.

7. GOULART, G.C. Procedimentos técnicos em pediatria. In: MURAOVSCHI, J. Emergências em pediatria. 4. ed. São Paulo, Sarvier, 1984. p.59-62.

8. HOWARD, J. Atencion del prematuro. 2. ed. Santiago, Universidad Católica, 1966.

9. HUGHES, W.T. \& BUESCHER, E.S. Trato gastrintestinal. In: Procedimentos ténicos em pediatria. 2. ed. Rio de Janeiro, Interamericana, 1983. cap.11, p.234-42.

10. MERIGHI, M.A.B. Conhecimento que a atendente que trabalha em berçário de prematuro tem sobre certos cuidados de enfermagem dados a esse recém-nascido. São Paulo, 1984. p.35-6. (Dissertação de mestrado. Escola de Enfermagem da USP).

11. ORLANDI, O.V. O prematuro. Rio de Janeiro, Capitolio, 1954. p.102-5.

12. PHILIP, A.G.S. Alimentação. In: Neonatologia. Rio de Janeiro, Guanabara Koogan, 1979. cap.11, p.102-4.

13. WAECHTER, H.E. \& BALLARD, R. Assistência de enfermagem a prematuros. In: WAECHTER, H.E. Enfermagem pediátrica. 9. ed. Rio de janeiro, Interameriana, 1979. cap.11, p.183-96.

14. WATANABE, T.M. et alii. Rotinas e técnicas de enfermagem neonatal. In: SEGRE, C.A.M. \& ARMELliMI, P.A. RN. São Paulo, Sarvier, 1981. cap.28, p.638-39.

15. WILLETT et alii. Enterol nutrition. In: Manual of neonatology intensive care nursing. Boston, Little, Brown 1986. cap.6, p.66-73.

16. ZIEGEL, E.E. \& CRANLEY, M.S. Alimentação do recém-nascido. In: Enfermagem Obstétrica. 8. ed. Rio de Janeiro, Interamericana, 1985.

17. ZIEMER, M. \& CARROL, J.S. Infant gavage reconsidered. Am. J. Nurs, New York, 78(9):1543-44, Sept. 1978.

Recebido para publicação em 06-05-87 